\title{
O JAPONES E O SEU RELACIONAMENTO COM A NATUREZA
}

\author{
(Conferéncia proferida pelo \\ Prof. Tooru Asami, Prof. visi- \\ tante da Universidade Gifu, \\ junto à USP, no dia 25 de \\ junho de 1983, no Gremio \\ Urasenke de São Paulol
}

Hoje, quero falar um pouco sobre a maneira segundo a qual o japonês se relaciona com a natureza.

Quantas pessoas existem entre os 120 milhões de habitantes do Brasil, que apreciam a beleza da lua numa noite de luar? E no mundo inteiro, quantas haveria? Não precisaria ser a lua. Desde quando a humanidade teria adquirido o hábito de observar as coisas que o rodeiam, sentir e apreciar as suas belezas a ponto de exclamar: Que linda paisagem!

E natural que a maneira de sentir difere com o ambiente. Deve haver diferença para o homem que vive no pólo norte, cercado de neve e gelo, para aquele que vive no deserto, bem como para aquele que vive numa pequena ilha do imenso oceano. Ou ainda, os que sofrem por não terem o que comer, os que são obrigados a trabalhar o dia inteiro, ou mesmo os que estão condicionados à vida de escravidão naturalmente não têm condições para uma contemplação da paisagem. Isto seria um prazer supérfluo.

A humanidade demorou muito para começar a pintar a natureza como tema principal. De fato, os desenhos encontrados nas cavernas da idade primitiva eram figuras de animais. Supōe-se entretanto, que os primitivos não os desenharam ou esculpiram nas rochas pensando na graciosidade ou beleza destes animais. 
Nas civilizações antigas, anteriores à era cristã, pintavam-se animais, aves, flores e arbustos. Entretanto, essas figuras näo passavam de meros enfeites que adornavam as bases dos altares e as tumbas, ou apenas cenários de ação dos heróis e deuses. O tema principal cabia sempre aos deuses ou aos seres humanos.

Foi somente após a Renascença, na época da arte barroca, no século XVII, que a paisagem começa a ser o tema de pintura na Europa. Isto, no entanto, ocorreu na China mais cedo: no fim da dinastia Tang, no século IX. Durante a dinastia Sung, na segunda metade do século $X$, a corrente principal da pintura vem a ser o Sansuiga (Pintura em preto ' e branco de montanhas, águas, lagos, mares,à tinta nanquim). No Japão, através da influência chinesa, começa a aparecer o Sansuiga, mais ou menos no século XIII. No século XV, já havia conquistado uma posição definida.

No caso da literatura, temos um aspecto um pouco diferente do da pintura.

A literatura arcaica concernente a cada povo apresenta-se principalmente em forma de poesia. Nesta poesia, não era comum exaltar a natureza. Mesmo na literatura européia, o tema principal das poesias repousava inicialmente nos feitos dos deuses e heróis. Mesmo mais tarde, quando apareceram as obras que cantavam o sentimento e a vida do homem, ou ainda, depois do século XIX, quando a prosa tornou-se o gênero principal, raramente enalteciam a natureza. Mesmo assim, a presença da natureza se justificava apenas para apresentar o local em que o personagem principal iria atuar. Uma tendência semeIhante se repetia na literatura de outras regiões, se bem que, na poesia chinesa, era constante a referência à natureza. Isto aconteceu desde os séculos VI e VII. Mesmo nestes casos, servia-se da paisagem para exprimir sentimentos que provêm da relação entre o "eu" e o "nãoeu", tais como: a tristeza pela separação com um amigo, a saudade da terra natal ou o amor.

Porém, no Japão, desde os tempos remotos, vinha sendo cultivada a poesia cuja temática retratava o sentimento do homem com relação à natureza (Jokeika). Para isso talvez tenha influído a atmosfera japonesa, isto é, o seu ambiente geográfico.

Como todos sabem, o Japão é um arquipélago estreito e comprido, que se situa no Oceano Pacífico, à beira do Continente Asiático. As correntes quentes do mar que o circundam, fluem do sul para o norte. A antiga capital, Kyoto, que se situa a uma latitude norte de $35^{\circ}$ correspondente à de Buenos Aires, no Continente Sul-Ameri- 
cano, tem suas estaçőes do ano - primavera, veråa, outono e inverno - bem caracterizadas, alterando-se sistematicamente.

$\mathrm{Na}$ atual cidade de Kyöto como exemplo, a temperatura média mensal varia entre $3,9^{\circ} \mathrm{C}$ em janeiro, o mês mais frio, e $27,5^{\circ} \mathrm{C}$ em agosto, o mês mais quente. Esse calor pode ser igualado às temperaturas médias mensais observadas em Manaus e São Lu is, as quais chegam, no máximo, a $27,9^{\circ} \mathrm{C}$ e $27,2^{\circ} \mathrm{C}$ respectivamente. $\mathrm{O}$ calor de Kyōto ultrapassa a do Rio de Janeiro que chega a $26,1^{\circ} \mathrm{C}$ em feve:reiro, e a de Santos que chega a $25,9^{\circ} \mathrm{C}$. Quanto às temperaturas médias baixas, a variação é de $20,8^{\circ} \mathrm{C}$ no Rio, $19,2^{\circ} \mathrm{C}$ em Santos e $17^{\circ} \mathrm{C}$ em Florianópolis e mesmo em Porto Alegre onde a diferença é notável, fica em $14,2^{\circ} \mathrm{C}, 0$ que comprova năo haver condiçőes para uma comparação. A diferença entre as temperaturas máximas e mínimas em Kyōto chega a $24^{\circ} \mathrm{C}$. No Brasil a diferença maior é de $10,6^{\circ} \mathrm{C}$, em Porto Alegre. Em Buenos Aires, que se situa na mesma latitude de Kyôto, há uma variaçáo de $23,6^{\circ} \mathrm{C}$ para $10,3^{\circ} \mathrm{C}$. No Japão, a temperatura média varia de $1^{\circ} \mathrm{C}$ a cada semana.

A mudança de estaçס̄es é consideravelmente regular no Japão. A sua flor representativa é a cerejeira que floresce na primavere. Este florescimento começa nas regiões mais quentes do sul e prossegue gradativamente para 0 norte, nas regiőes mais frias. Mas dentro da mesma região, o desabrochar das cerejeiras ocorre quase no mesmo dia do ano com uma variação de 3 a 4 dias e, provoca motivo de transtorno se a variação chegar a uma semana.

Do mesmo modo, é quase sempre na mesma época que aparecem os primeiros rouxinóis, que começa a estação chuvosa, que as andorinhas imigram, que as cigarras começam a cantar, que se inicia o período das geadas e das neves. A modificação da natureza desempenha o papel do calendário.

Assim, esta mudança ordenada e um tanto brusca da natureza define o ritmo de vida do povo. Até há pouco tempo, existia no Japão o costume do Koromogae, segundo o qual todas as pessoas mudavam, todos ao mesmo tempo, suas vestimentas, adequadas às estaçð̃es. O fato de os japoneses estarem sempre irriquietos constitui provavelmente uma conseqüência desta mudança vertiginosa e ordenada da natureza, que os persegue.

As flores, as aves e os insetos se apresentam diante de nossos olhos, todos os anos na mesma época, na sua maioria, num espaço de tempo muito curto. Até recentemente, cada espécie de verdura , fruta: e peixe só podia ser consumido num período curto do ano Ger- 
tos aspectos da vida do homem no Japão são freqüentemente limitados pela repentina transformação da natureza. Vivendo no Japão, nossos olhos voltam-se para as mudanças da natureza mesmo involuntariamente.

Há aproximadamente 1.100 anos, logo no in ício do século $X$, foi composta, por ordem do Imperador, a coletânea de poemas "KokinWaka-Shü", que posteriormente, se tornou o modelo dos 20 ChokuSen-WakaShū (Coletânea de poemas japoneses organizada por ordem do imperador). Nesta coletânea, cerca de 1.100 poemas foram classificados por temas e reunidos em 20 volumes, como segue: os primeiros seis volumes contêm poemas classificados conforme as quatro estaçס̋es do ano (Vols. I e II - primavera; III - verao; IV e V - outono; e VI - invernol, sendo que o volume VII compõe-se de poemas sobre festejo; o volume VIII sobre despedida; o volume IX sobre viagens; 0 volume $X$ de poemas contendo jogo de palavras; os volumes $X I$ ao $X V$ versam sobre o amor; o volume $X V \mid$ sobre elegia e os volumes $X V I I$ e XVIII sobre temas variados; no volume $X I X$ estão outras formas poéticas que não sejam o Tanka (poemas formados por 31 sflabas, dispostas em versos de 5-7-5-7-7 sílabas) e no volume $X X$ estão compilados os poemas recitados nas cerimônias da casa imperial. Isto significa que, em mais da metade dos poemas japoneses, predominam os temas sobre o amor e as estaçǒes do ano. A classificação dos poemas de acordo com o tema era feita há muito tempo na China, mas nela não se encontram títulos referentes às estações do ano. No Japåo, existe a coletânea "Shinsen Man-Yō Shü", compilada um pouco antes do "Kokin-Shü", organizada em dois volumes. Cada um dos volumes divide os poemas de acordo com os temas referentes a primavera, verão, outono, inverno e o amor. E dos 20 volumes de Man-Yō-Shü, coletânea de poemas que registra seus últimos poemas datados de 759 , os volumes VIII e $X$ já se acham classificados conforme as quatro estações do ano.

Vamos apréciar um dos poemas do Kokin-Shü.

nQ 1 UMEGA ENI KIIRU UGUISU HARU KAKETE NAKEDOMO IMADA YUKIWA FURITSUTSU.

O rouxinol que vem e pousa no galho da ameixeira, canta como se estivesse invocando a primavera, mas os flocos de neve continuam a cair. 
Encontramos, também no Man-Yö-Shū, um poema similar:

\section{nO 2 UCHIKIRASHI YUKIWA FURITSUTSU SHIKASUGANI WAGUIENO SONONI UGUISU NAKUMO}

Tudo ao redor está escuro e a neve continua a cair incessantemente. Porém, no meu jardim,o rouxinol já começa a cantar.

O inverno no Japão é muito rigoroso. As casas antigas, mesmo as dos nobres, não tinham paredes. Os espaços entre os pilares eram preenchidos por portas corrediças, os quartos quase não possuíam divisões e o teto era alto - era nesse espaço amplo e vazio que os antigos viviam. Para o aquecimento do ambiente, dependiam somente do carvão. As vestimentas não aqueciam como as de hoje. Vivendo nessas condições, é com muita ansiedade que todos aguardavam pela chegada da primavera, com flores desabrochando, os pássaros cantando e os brotos verdes germinando todos ao mesmo tempo.

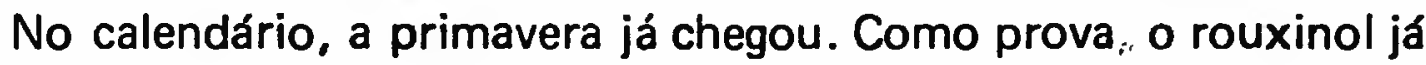
está cantando no meu jardim. O rouxinol é um pássaro do tamanho de um pardal, de cor amarelo esverdeado, muito gracioso. Na primavera ele vem da colina para o povoado e canta "Ho hokekyo", com um lingo gorjeio. A onomatopéia "Ho hokekyo", que representa o cantar do rouxinol se deu somente com a introdução do Budismo no Japão. Para os japoneses, o trinado do rouxinol se assemelha com o Sutra supremo budista Ho-ke-kyō. Dal surgiu o nome "pássaro que recita o sutra"

O canto melódico do rouxinol só pode ser ouvido num certo período da primavera. Depois, o som muda para um simples "kekyo, kekyo" e, com o aproximar do verão, desaparece da vista das pessoas. $O$ rouxinol não costuma voar em bando. $O$ canto que se ouve é de um único pássaro. As vezes ouve-se, ao longe, o canto de um outro. Com o canto do rouxinol, ouve-se o aproximar da primavera, mas, fora, ainda dançam flocos de neves remanescentes do inverno. Mas de maneira nenhuma esta neve chegará a se acumular. Diferentemente da neve de flocos pequenos e secos do inverno, ela é grande, cristalizada e aquosa, derretendo-se rapidamente assim que chega ao solo. Cada floco desta neve, que já não gela o corpo até os ossos, cai, esvoaçando, soprado pelo vento da primavera. Neste ponto de encontro em que o inverno está para ir e a primavera para chegar, é que os homens encontram a alegria de receber a primavera. 
Naturalmente, para os povos que enfrentaram um rigoroso inverno, aguardar a primavera é uma alegria em comum. Existe uma frase em alemăo que diz: "Maravilhoso mês de maio". A sensação de liberdade que se sente com o clima mais quente, com as mais variadas flores se abrindo, os pássaros cantando sem cessar, deve ser sempre e, em qualquer lugar a mesma alegria para todos aqueles que ficaram aprisionados durante um longo inverno.

Mas os poemas acima referidos são um pouco diferentes. A neve continua a cair. Representa um cenário de inverno. E nele se ouve o gorjeio do rouxinol. A verdadeira primavera já está quase aí. $O$ rouxinol anuncia antecipadamente a aproximação da primavera. E é nessas delicadas transformações das estações que as pessoas encontram a alegria.

A neve representa o inverno; o rouxinol é o pássaro do in ício da primavera. No Japão, cada elemento da natureza, torna-se o símbolo das estações. Como exemplo representativo tem os "Setsugekka" (neve-lua-flor) ou "Kachōfügetsu" (flor-ave-vento-lua).

Nem é necessário falar sobre as flores, pois elas so florescem numa determinada época do ano. No Japão, não existem flores como a rosa e a açucena do Brasil que florescem o ano inteiro. Dentre as flores, a flor de ameixeira, que floresce no início da primavera, depois de todo um inverno em que não florescem flores, era a preferida. A ameixeira não é uma planta nativa do Japáo. Há aproximadamente 1.300 anos, quase na era Nara, ela foi importada da China. Era apreciada entre os nobres da época como objeto estrangeiro de luxo. Enquanto não se notavam outras flores, brotos ou folhagens, a ameixeira florava com suas flores brancas e elegantes, exalando um perfume intenso.

Se a flor é o símbolo das estações que se transformam, quanto mais curto o período de sua floração, mais se torna representativa. É por isso que o "Sakura" (flor de cerejeira) centraliza o interesse das pessoas.

A flor de cerejeira, desde a sua floração até o completo desfolhamento, dura de uma semana la dez dias. Não apresenta diferenças de duração de florescimento de uma árvore pera outra. $O$ desabrochar acontece de uma vez, deixando as árvores de cerejeira repletas de flores. Em seguida desfolham. Neste período o clima também muda vertiginosamente. Se faz um ou dois dias seguidos de céu claro e calmo, seguem-se um ou dois dias nublados e com ventos fortes seguidos de chuvas fortes como tempestades. Assim permanece por 
um ou dois dias e, em seguida, voltam os dias nublados para enfim haver a completa normalizaçåo do tempo. Com as chuvas, as flores se desbotam e não resistindo às monçőes, desfolham-se e caem como chuvas de pétalas. Diante dessas circunstâncias,os japoneses contemplam o céu e se sentem ora felizes ora preocupados.

Os pássaros, como o pardal e o corvo, que cercam o cotidiano das pessoas, longe de estimularem a sensibilidade face às estaçס̃es, ao contrário, nem sequer surgem no mundo literário. Esses acontecimentos cotidianos começam a aparecer na literatura, somente há uns 300 anos, na era Edo. Nessa época começou-se a observar qual a estação em que o seu comportamento mais os caracterizavam.

Porém, há mais ou menos 1.000 anos, os pássaros imigrantes que eram vistos e ouvidos somente em determinadas épocas, o cuco do verão, o pato silvestre do outono, juntamente com o rouxinol constituíam símbolos das estações.

Podemos entender porque essas flores e aves eram consideradas símbolos das estaçðes. Mas e no caso da lua? Ela aparece $o$ ano inteiro, ora crescente, ora minguante. $O$ costume de admirar a beleza da lua foi introduzido da China. Antes desse acontecimento, os japoneses não se interessavam por ela a não ser porque iluminava a noite, marcava o tempo e por sua relação com as marés altas e baixas.

Todavia, assim que este hábito se difundiu, ajustou-se completamente aos gostos dos nobres $e$, posteriormente, dos japoneses em geral. Há aproximadamente dez séculos, os japoneses começaram a apreciar a beleza da lua.

E ainda, descobriram que a fisionomia da lua adquiria aspectos diferentes conforme as estações. Isto só pode ocorrer no caso do Japão. O mais belo é o luar de outono, como lhes foi ensinado pelos chineses. É uma lua clara num ar límpido. Mas a lua enevoada da primavera - "Oborozuki" - - também era muito apreciada pela sua beleza peculiar.

Não se observa muito a lua no verão. Ela simbolizava as noites curtas. A lua de inverno também não era muito vista. Somente os nobres, nos fins do século XII e no século XIII, descobriram a beleza da solidão e da austeridade, passando a cantar a lua de inverno.

0 mesmo acontece com referência ao vento.

\section{n? 3 AKAAKATO HIWA TSURENAKUMO AKINO KAZE}

sol com os seus raios vermelhos brilha sem dó nem compaixão, 
mas o que sentimos na pele não é mais aquele vento causticante do verão.

A obra de 1689, é um "Haiku" (poema de 17 sílabas), mas èra desde há muito tempo cantada no mundo do "Tanka" (poema de 31 sílabas).

\section{n? 4 AKI KINUTO MENIWA SAYAKANI MIENEDOMO KAZE- NO OTONIZO ODOROKARENURU}

A chegada do outono só é revelada pelo calendário, todo o ambiente que se vê tem aspecto de verão, mas o vento que sopra acusa a presença do outono.

Sentimos na pele a diferença dos ventos do outono e do veráo: distingue-se o vento de ontem, de uma semana atrás e de hoje, e assim percebe-se os sinais do outono. Desde muito cedo nossos antepassados possuiam esse dom de distinguir as sensações mais sutis. Dentro daquilo que parecia algo contínuo, captavam a sutil diferença entre o inverno e a primavera, o veráo e o outono, e tentavam apreen. der como símbolos diversos.

Desta forma, as expressões relacionadas com a natureza do tipo: "Já estamos na primavera" ou "O verão está terminando" têm conotações diferentes de outras expressóes do tipo: "Que agradável paisagem!" ou "Que linda lua!" Os primeiros exemplos estáo mais relacionados com a vida e o comportamento do homem enquanto que as expressões de apreciação da paisagem estão mais profundamente ligadas à objetividade ou à postura de integraçăo com a natureza.

Assim no Japão, desde há muito tempo podiam ser vistos poemas como estes que cantavam a beleza da natureza. Porém, o fato de descrever o aspecto da natureza não significa que seja um poema que cante a beleza da natureza (Jokeika).

\section{n? 5 SAIGAWAYO KUMOTACHIWATARI UNEBIYAMA KONO. HA SAYAGINU KAZE FUKANTOSU}

Do Rio Sai, as nuvens vão se formando sucessivamente e as folhagens da montanha Unebi começam a farfalhar. Deve começar a soprar um vento como o de uma tempestade.

Pode-se dizer que este poema canta o estado apreensivo em que se encontra a natureza, com ventos em rajadas, momentos antes da mudança do tempo, entretanto, na obra Kojiki (Crônica histórica 
clássica datada do ano de 712), este poema tenta transmitir sutilmente o sinal de rebelião de um golpe de Estado.

\section{n? 6 TAKAMATONO JOBENO AKIHAGI ITAZURANI SAKIKA CHIRURAMU MIRU HITO NASHINI}

As flores da lespereza que florescem abundantemente nos campos de Takamato, sem ter alguém para elogiá-las, neste momento devem estar desfolhando-se inutilmente.

Este poema evoca as flores de lespereza do campo longínquo; mas é um poema que lamenta a morte de um príncipe que viveu naquéla redondeza. Não pode ser considerado um "Jokeika"

\section{n! 7 HIMUGASHINO NONI KAGIROINO TATSUMIETE KAERI. MISUREBA TSUKI KATABUKINU}

O lado leste do céu começa a clarear e vê-se a névoa fina pairando na campina. Olhando para trás, no lado oeste do céu, a lua declina-se palidamente. É um poema de enfoque amplo que visualiza desde o horizonte leste ao oeste.

Existe também um "Haiku" que enfoca um cenário semelhante:

\section{nO 8 NANO HANAYA TSUKIWA HIGASHINI HIWA NISHINI}

Mas existe uma grande diferença entre ambos. Em primeiro lugar, a estação é diferente. A estação enfocada no primeiro poema é o inverno, enquanto que do "Haiku" é a primavera. O horário do primeiro é o amanhecer e do segundo, o entardecer. A flor de colza ( $\mathrm{Na}$ nohanal é uma erva que na sua extremidade dá muitas flores pequenas de cor amarela. De suas sementes extrai-se o óleo comestível de fina qualidade. A raiz e o caule servem de adubo. Após o cultivo, colhem-se as sementes, revolve-se a terra e o resto é utilizado como adubo. Por isso, no início da primavera, no local do arrozal produzido entre o verão e o outono, tudo fica coberto pelas flores de colza como se um tapete amarelo vivo tivesse sido estendido. Neste lugar, o sol do entardecer brilha com os seus raios avermelhados e do lado este, surge uma grande lua branca. Este poema é de Buson, cuja profissão era a de pintor Realmente este poema é uma pintura. Este quadro de paisagem não é pomposo, mas o colorido é abundante. Como se trata de um entardecer do in ício da primavera, as cores não 
estão muito nítidas. Mostra 0 aspecto de tranqüilidade e silêncio na neblina do entardecer

Quanto ao poema n? 7, foi composto em 31 de dezembro do ano de 692, por Kakino Motono Hitomaro, considerado o maior poeta da antologia Manyōsh $\bar{u}$, e se refere a uma caçada em que foi como acompanhante, do príncipe Karuno Miko (posteriormente Imperador Monmu\}. O local é o mesmo em que há alguns anos, o poeta acompanhou o Príncipe Kusakabeno Miko, pai do príncipe Karuno Miko, falecido prematuramente. Neste local, Hitomaro, rememorando os tempos passados, compôs um "Chōka" (poema formado por 5 e 7 sílabas repetidas por mais de três vezes e que termina com dois versos de 7 sílabas). Neste "Chōka", ele acrescentou mais quatro "Tanka" O primeiro "Tanka" se refere aos súditos do Imperador que, rememorando o passado, passam a noite em claro; o segundo "Tanka", sobre a ida ao mesmo local como recordação do pai do príncipe; o terceiro, o poema citado; e o quarto "Tanka", sobre a hora em que partiu o príncipe Kusakabeno Miko para a sua caçada matinal e sobre o estado de espírito do momento da partida para tal caçada.

Estes poemas são muito pobres em colorido. De um modo geral, os poemas clássicos do Japão não possuem um colorido abundante, esses surgem somente em torno do ano de 750. Este poema também se assemelha ao mundo do Sumiê, onde só se pode distinguir o contorno do claro e do escuro dentro de uma luminosidade pálida: o sol ainda não despontou; a lua começa a perder a sua claridade. Entretanto, não se trata do mesmo estado de silêncio absoluto de Buson, em que não se ouve um único ruído.

Um grande número de acompanhantes do príncipe está acampado. Pela seqüência dos poemas, podemos ver que a comitiva já está acordada e pronta para a caçada. Os cavalos relincham, as pessoas se movimentam apressadamente, 0 fogo aceso em diversos lugares. Os poemas de Hitomaro, em sua grande maioria, têm como grande cenário o movimento de grupo de pessoas e se apresentam em forma de porta-voz desses grupos. Não se trata simplesmente de pintura de uma paisagem. É um grito feroz de ação conjunta do príncipe, dos súditos e do autor. Este poema também năo é um "Jokeika"

\section{n! 9 NUBATAMANO YONO FUKEYUKEBA HISAKI OURU KIYOKI KAWARANI CHIDORI SHIBANAKU}

A noite avança e, na margem do rio cristalino iluminado pela lua, 
a tarambola canta intensamente.

Este "Tanka" é de Yamabeno Akahito, quando, no verão do ano de 725, acompanhou a comitiva da Imperatriz Jitô a Yoshino. 0 Palácio de Yoshino se localizava perto do rio Yoshino. Os rios do Japåo, diferentes dos rios do Brasil, são de curta extensão e fluem em terrenos bruscamente inclinados. Por isso o fluxo das águas é rápido e suas águas deixam transparecer os leitos. E no leito dos rios há grandes quantidades de rochas e pequenas pedras. Nas margens dos rios há cascalhos descobertos pelas águas que se estendem até os bancos de areia. Ai crescem pequenas plantas. Naturalmente, quando chove torrencialmente, num instante, o volume das águas aumenta e as margens do rio ficam cobertas. Quando a água diminui de volume, novamente aparecem os cascalhos dos rios. As regiões próximas ao Palácio Yoshino são chamadas de Miyataki onde enormes rochas se salientam e em lugares estreitos as águas caem em forma de quedas d'água.

Como se tratava da comitiva do Imperador, supõe-se que muitos cortesãos o acompanhavam. Deixavam a capital e pernoitavam fora desse palácio por alguns dias. A noite talvez banquetes alegres se repetissem. mas o autor nada tem a ver com essa animação. $A$ tarambola é um pequeno pássaro aquático que saltita junto às águas e se alimenta de insetos. Curiosamente, age durante a noite. $O$ seu cantar tem um som fraco e baixo.

Para poder ouvir o cantar baixinho desse pássaro que se confunde com o som da corrente das águas do rio, o estado de espírito do autor e o ambiente devem estar muito tranqüilos. Ele foge das pessoas e, à noite, sozinho, vem pra perto do rio. Lá adiante, vêem-se as luzes do palácio. Talvez se possa ouvir ao longe, risos e gargalhadas das pessoas que se divertem. Distante de tudo isso, junto às águas e ao rio iluminados pela brancura da lua. e ainda, o cantar da tarambola.

Exatamente nesse instante, se estabelece a existência de um indivíduo. É desta forma que surge um "Jokeika"

Os japoneses vieram,ao longo do tempo, adquirindo o hábito de se voltar para a natureza de maneira desprendida e tentar integrar-se na beleza da natureza.

Naturalmente, há diversificações na forma de aceitação da natureza.

nO 10 HARUNO SONO KURENAI NIOU UMENO HANA SHITATERU MICHINI IDETATSU OTOME 
No jardim em que novos brotos de arbustos e árvores começam a recuperar o verde, florescem as flores de ameixeira vermelha em sua plenitude. As áreas que ficam sob essas flores vermelhas dão-nos a impressão de terem sido tingidas de vermelho. E a jovem que ai surge, vestida luxuosamente em estilo chinês, será filha de nobres? Talvez ela própria tenha surgido sem motivo ou objetivo algum. As figuras humanas são partes do cenário da alegre e calma primavera integrando-se na natureza. Náo se trata de uma silhueta humana que demonstre uma ação ou vontade própria.

\section{nO 11 MIWATASEBA YANAGI SAKURAO KOKIMAZETE MIYA- KOZO HARUNO NISHIKI NARIKERU}

O brocado é um luxuoso tecido tradicional da China, em verde, vermelho e amarelo ou com linhas douradas e prateadas, de um colorido muito vistoso. O verde dos brotos do salgueiro, a cor rosa das flores de cerejeira, olhando tudo isso do alto, vemos que a cidade inteira parece transbordar com este colorido. É plenitude da primavera. Da era Nara ao in ício da era Heian, temos a época áurea dos nobres. Foi também uma época de estagnação e paz. Eles paralisaram as atividades. Na cidade ou dentro de casa, se levassem uma vida de contemplação, reinava a paz. O luxo e a riqueza começam a ser acrescidos.

\section{nO 12 HARUNO YONO YAMIWA AYANASHI UMENO HANA IROKOSO MIENE KAYAWA KAKURURU}

A escuridão significa uma noite em que a lua não aparece. As noites de primavera são mais quentes, sem ventos e por causa da neblina concentrada, sentimos maior escuridão. A flor branca da ameixeira também se esconde dentro dela. Não há nenhuma cor. Porém o aroma inconfundivel flutua no ar. Por mais que fitemos com os olhos, as flores da ameixeira não são visiveis. Porém dentro desta escuridão, como uma ilusão, não surgiria cada uma das flores brancas da ameixeira? Este é um mundo ilusório. Eu sinto neste poema uma indescritivel e profunda sensualidade.

Este esplendor foi desaparecendo gradativamente com o enfraquecimento do poder social dos nobres.

\footnotetext{
"SO SE APRECIA A FLOR EM SUA PLENITUDE, A LUA SEM SOMBRA?"
} 
Será que podemos somente apreciar as flores em sua plenitude ou a lua cheia? Não será nas flores do in ício da floração, ou no momento em que começam a despetalar, ou na lua minguante que se encontra maior fascínio? Esse tipo de perguntas começa a surgir.

Os olhos que observam a natureza se tornam cada vez mais aguçados. E começamos a descobrir o belo nas paisagens desoladas a tristes.

\section{nO 13 SHIGANO URAYA TOOZAKARIYUKU NAMIMAYORI KOORITE IZURU ARIAKENO TSUKI}

A noite avança e o frio torna-se mais rígido; no Lago Biwa, as águas começam a congelar pelas margens e este gelo vai se estendendo lago adentro. $E$ as ondas que se quebravam nas margens vão aos poucos se distanciando. Não se ouve mais o barulho das ondas. E, ao longe, dentre as ondas, surge a lua gélida e de forma reduzida.

A hora mais fria do inverno é aquela entre a madrugada e o amanhecer. Um vento frio sopra no lago; o céu límpido - certamente é um cenário que sugere o frio. $E$ então surge a lua delgada, completamente clara como se estivesse congelada. Novamente desaparecem as cores, o som e a sombra. É um cenário solitário e até aterrorizador.

Mas, na realidade, as águas do Lago Biwa não se congelam. As ondas que dizem se distanciarem săo fantasias e a lua que surge congelada também pertence a um mundo subjetivo. $O$ autor não foi ao local e não se inspirou na paisagem real para compor este poema. $E$ um mundo imaginário composto dentro da cabeça do autor.

Por que o autor teria imaginado tal paisagem? Talvez porque essa seja a forma mais apropriada para simbolizar o seu sentimento. A pintura "Sansuiga" da China também abandonou o realismo no in icio. É elaborada com subjetividade. Emocionamo-nos com uma certa paisagem. Há pouco, citei que era de maneira destituída de vontade própria, mas, na realidade, como somos seres humanos com sentimentos, nos emocionamos, através desse sentimento, com as paisagens da natureza.

Os seres humanos criaram um cenário para expressar os sentimentos pessoais, sentimentos estes que não refletem a alegria esplendorosa nem tampouco uma emoção pessoal profunda com relaçao ao outono que se distancia. Trata-se do Belo encontrado dentro da severidade da desolação, do sentimento que vem da decadência dos nobres, este calcado no ensinamento de destruição do mundo pre- 
gado pelo Budismo. Baseia-se no sentimento de tristeza e de solidáo. Logo após, surge a época de aperfeiçoamento do teatro Nō e do Sadó (Cerimônia do Chá). 